\title{
DEAD-box helicase 27 enhances stem cell-like properties with poor prognosis in breast cancer
}

Shan Li ${ }^{1}$, Jinfei Ma ${ }^{1}$, Ang Zheng ${ }^{1}$, Xinyue Song ${ }^{2}$, Si Chen ${ }^{3^{*}}$ and Feng Jin $^{1^{*}}$ (e)

\begin{abstract}
Background: Although the rapid development of diagnosis and treatment has improved prognosis in early breast cancer, challenges from different therapeutic response remain due to breast cancer heterogeneity. DEAD-box helicase 27 (DDX27) had been proved to influence ribosome biogenesis and identified as a promoter in gastric and colorectal cancer associated with stem cell-like properties, while the impact of DDX27 on breast cancer prognosis and biological functions is unclear. We aimed to explore the influence of DDX27 on stem cell-like properties and prognosis in breast cancer.

Methods: The expression of DDX27 was evaluated in 24 pairs of fresh breast cancer and normal tissue by western blot. We conducted Immunohistochemical $(\mathrm{IHC})$ staining in paraffin sections of 165 breast cancer patients to analyze the expression of DDX27 and its correlation to stemness biomarker. The Cancer Genome Atlas-Breast Cancer (TCGABRCA) database and the Clinical Proteomic Tumor Analysis Consortium (CPTAC) database were used to analyze the expression of DDX27 in breast cancer. Kaplan-Meier survival analysis were used to investigate the implication of DDX27 on breast cancer prognosis. Western blot, CCK-8 assay, Transwell assay and wound-healing assay were carried out to clarify the regulation of DDX27 on stem cell-like properties in breast cancer cells. Gene Set Enrichment Analysis (GSEA) was performed to analyze the potential molecular mechanisms of DDX27 in breast cancer.

Results: DDX27 was significantly high expressed in breast cancer compared with normal tissue. High expression of DDX27 was related to larger tumor size $(p=0.0005)$, positive lymph nodes $(p=0.0008)$, higher histological grade $(p=0.0040)$, higher ki-67 $(p=0.0063)$ and later TNM stage $(p<0.0001)$. Patients with high DDX27 expression turned out a worse prognosis on overall survival (OS, $p=0.0087$ ) and disease-free survival (DFS, $p=0.0235$ ). Overexpression of DDX27 could enhance the expression of biomarkers related to stemness and promote stem cell-like activities such as proliferation and migration in breast cancer cells.
\end{abstract}

Conclusion: DDX27 can enhance stem cell-like properties and cause poor prognosis in breast cancer, also may be expected to become a potential biomarker for breast cancer therapy.

Keywords: DEAD-box helicase 27 (DDX27), Breast cancer, Stem cell-like properties, Prognosis

\footnotetext{
*Correspondence: jingsisi8902@126.com; jinfeng@cmu.edu.cn

1 Department of Breast Surgery, The First Affiliated Hospital of China

Medical University, Shenyang, Liaoning Province, China

${ }^{3}$ Department of Microbial and Biochemical Pharmacy, School

of Pharmacy, China Medical University, Shenyang, Liaoning Province, China

Full list of author information is available at the end of the article
}

\section{Background}

Breast cancer has already surpassed lung cancer and developed into the major malignant tumor in women all around the world with 2.3 million new cases in 2020 based on GLOBOCAN 2020 [1]. Although the rapid development of diagnosis and treatment has improved prognosis in early breast cancer, challenges from 
different therapeutic response remain due to breast cancer heterogeneity.

DEAD-box helicase 27 (DDX27) pertains to the DEAD-box RNA helicases family, which is a classical ATP-dependent helicases family containing conserved D-E-A-D (Asp-Glu-Ala-Asp) sequences. This family has been confirmed to participate in various processes containing RNA transportation, RNA degradation, glucose metabolism, lipid metabolism, ribosome biosynthesis, tumorigenesis, cancer development and so on [2-8]. DDX27 was proved to take part in the processes of ribosome biogenesis, which performed an important function in cell proliferating. DDX27 could regulate the 47S ribosome RNA formation and associated with PeBowcomplex independently [9]. In the process of skeletal muscle myogenesis, DDX27 was reported to influence ribosome RNA maturation, ribosome biogenesis and specific transcription [10]. DDX27 was also related to the development of malignant tumor. DDX27 had been confirmed to promote the development and metastasis in hepatocellular carcinoma and gastrointestinal cancer with poor prognosis [11-13]. Until now, the status of DDX27 expression and its implication on breast cancer remains unclear.

Breast cancer stem cells refer to a fraction of cells with strong self-renewal capacity and a huge potential of multiple differentiation in breast cancer, which can promote the courses of tumorigenesis, development, metastasis and drug resistance [14-16]. Studies proved that members of DEAD-box RNA helicases family could affect the biological behavior of cancer stem cells in various cancers [17-19]. The only member of DEAD-box RNA helicases family which has exactly effects on breast cancer stem cells is DDX17, who can enhance stem cell-like activities by combining with SOX2 or mechanism of promoting stem-like properties under hypoxia [20, 21]. DDX27 was reported to promote stem cell-like characteristics and cause poor prognosis in gastric and colorectal cancer $[11,22]$, while the influence on stemness in breast cancer remains unclear. Hence, it is of great significance to explore the influence of DDX27 on tumorigenesis, progress and the association with stem cell-like properties in breast cancer, which might suggest a new idea for diagnosis and therapy.

In our study, DDX27 was highly expressed in both bioinformatic analysis and samples from breast cancer patients. High expression of DDX27 was firstly reported in breast cancer with the close connection to clinicopathological factors and caused a shorter survival. The expression of DDX27 was positively related to stemness biomarkers and promoted the stem cell-like activities. Furthermore, Gene Set Enrichment Analysis (GSEA) suggested that DDX27 might have an effect on breast cancer by various ways. Hence, DDX27 can enhance the stem cell-like properties meanwhile leading to a poor prognosis in breast cancer, which means DDX27 may become a potentially significant prognosis biomarker and therapeutic target.

\section{Methods \\ Bioinformatic analysis of DDX27 expression in breast cancer}

Gene expression data used for bioinformatic analysis were downloaded from The Cancer Genome Atlas-Breast Cancer (TCGA-BRCA) database (https://cancergenome. nih.gov/), which totally contained 1109 breast cancer and 113 normal samples. Integration and normalization of all data were performed by edgR package. After optimized the data from the same patients or formalin fixed samples, we finally obtained 1071 breast cancer samples and 113 normal samples for this analysis. The expression of DDX27 was analyzed between the 1071 breast cancer samples and 113 normal samples. Also, it was analyzed between the 113 normal samples and the matched breast cancer samples from the same patients. Further, the expression of DDX27 in breast cancer samples was extracted and classified into high and low expression by median value for the subsequent studies. UALCAN (http://ualcan.path.uab.edu/index.html) is an online analysis site of public oncology database. We used UALCAN to analyze the protein expression of DDX27 in breast cancer and normal tissue on the basis of Clinical Proteomic Tumor Analysis Consortium (CPTAC) database.

\section{Kaplan-Meier survival analysis and gene set enrichment analysis}

Kaplan-Meier Plotter (http://kmplot.com/analysis/) is an online database containing survival information and gene expression of various cancers [23]. This website was used to analyze the implication of different DDX27 expression on overall survival (OS) in the total population of breast cancer patients and the patients with different molecular subtypes. The cutoff value of high and low DDX27 expression was split by the website automatically and the results were shown by Logrank $p$ value. Gene Set Enrichment Analysis (GSEA) software 4.0.3 was performed to analyze the potential mechanism related to DDX27. Gene expression file for GSEA was the integrated and normalized data from BRCA-TCGA which were classified by DDX27 expression as we mentioned before. Another input file was the phenotype label contained 'high' and 'low' expression. Gene sets used in this analysis were downloaded from the Molecular Signatures Database (MsigDB). In order to ensure the creditability of the analysis results, we chose 1000 permutations in the software. Pathways which were significantly relevant to DDX27 
were chosen according to the normalized enrichment score (NES) meanwhile filtered by normalized $p<0.05$ and false discovery rate (FDR) $<25 \%$.

\section{Patients and tissue samples}

Under the permission from the Ethics Review Committee in the First Affiliated Hospital of China Medical University (AF-SOP-07-1.1-01), fresh cancer tissue with paired adjacent normal tissue $(n=24)$ and paraffin-embedded specimens $(n=165)$ were obtained. All included patients were pathologically diagnosed as invasive ductal carcinoma. None of the patients received breast-conserving surgery or neoadjuvant therapy. Twenty-four pairs of fresh specimens were collected within $30 \mathrm{~min}$ after surgery and 165 paraffin-embedded specimens for IHC were collected during Jan 2014-Dec 2015. Clinical and pathological information including age, tumor size, lymph nodes status, estrogen receptor (ER) status, progesterone receptor (PR) status, human epidermal growth factor receptor 2 (HER2) status, histological grade, ki-67 index, molecular subtypes and TNM stage was obtained from the Hospital Information System.

\section{Western blot}

Samples of tissue and cells were lysed by the compound of RIPA buffer and protease inhibitors (Sigma-Aldrich) for half an hour on ice after washed by phosphate-buffered saline (PBS) twice. Then the samples were centrifuged for $15 \mathrm{~min}$ in the condition of $14,000 \times g$ and $4{ }^{\circ} \mathrm{C}$. Protein from tissue and cells was quantified by $\mathrm{BCA}$ assay kit (Beyotime, Jiangsu, China). Protein with equal quantity was transferred onto the polyvinylidene fluoride (PVDF) membranes (Millipore, Bedford, MA) after electrophoresed by SDS-PAGE. The membrane was sealed with bovine serum albumin (BSA) and hatched with primary antibodies at $4{ }^{\circ} \mathrm{C}$ overnight, then the secondary antibodies at room temperature for one hour. The primary antibodies for experiments contained anti-DDX27 (1:2000, Abcam, USA), anti-SOX2 (1:1000, Proteintech, China), anti-OCT4 (1:1000, Cell Signaling Technology, USA) and $\beta$-actin (1:2000, Proteintech, China). Membranes were tested with an enhanced chemiluminescence detection kit (BOSTER, USA).

\section{Immunohistochemical staining}

Each paraffin-embedded sample was cut into $4 \mu \mathrm{m}$ sections, dewaxed routinely, and dehydrated with gradient ethanol. All sections were retrieved antigen in citrate buffer with high pressure. The sections were restored to room temperature and blocked the activity of endogenous peroxidase by $3 \%$ hydrogen peroxide. Then, all the slides were incubated with anti-DDX27 (1:2000, Novus Biologicals, USA) or anti-OCT4 (1:500, Cell Signaling
Technology, USA) at $4{ }^{\circ} \mathrm{C}$ overnight. On the second day, the sections were incubated with the secondary antibody at room temperature for one hour after washed by PBS. Sections were stained by diaminobenzidine (DAB) and counterstained by hematoxylin. Finally, slides were observed and captured with microscope.

\section{Evaluation of IHC}

Sections with DAB staining were evaluated blinded by two pathologists separately. The expression of DDX27 and OCT4 was assessed on the basis of the intensity of staining and the ration of positive stained cells. The intensity was divided into deep (3), medium (2), light (1) and negative (0). The positive stained cells were scored as follow: $0(0-5 \%), 1(6-25 \%), 2(26-50 \%), 3(51-75 \%)$, 4 (76-100\%). Final score of IHC staining was given by multiplication of percentage score and intensity. In this way, 165 patients were segmented into different groups in accordance with the expression of DDX27 and OCT4: high expression (final score $\geq 4$ ) and low expression (final score $\leq 3)$.

\section{Cell lines and culture}

Breast cancer cell lines MCF-7 and T47D gained from the American Type Culture Collection (ATCC) were cultured by high-glucose $(4.5 \mathrm{mg} / \mathrm{ml})$ DMEM (HyClone, USA) with $10 \%$ serum (Tianjin Hao Yang Biological Manufacture CL, China). MCF-7 mammosphere (MCF-7 MS) and T47D mammosphere (T47D MS) were inducted and cultured by DMEM/F12 (Gibco) with EGF $20 \mu \mathrm{g} / \mathrm{L}$ (Promega), b-FGF $10 \mu \mathrm{g} / \mathrm{L}$ (Promega) and 2\% B27 (Gibco). All of the cells used in our research were cultured in the condition containing $5 \% \mathrm{CO}_{2}$ and $95 \%$ air at $37{ }^{\circ} \mathrm{C}$.

\section{Cell transfection}

MCF-7 and T47D cells were transferred with overexpression and negative control plasmid (Genechem, Shanghai, China) using Lipofectamine 3000 (Thermo, USA).

\section{Wound-healing assay}

DDX27 over-expression and negative control plasmid were transfected into cells until 70\% confluency in sixwell plates. Linear "scratches" were created in straight lines with sterile tips. Then, cells were added serum-free medium after washing with PBS three times and photographed by microscope at $0 \mathrm{~h}, 24 \mathrm{~h}, 48 \mathrm{~h}$ and $72 \mathrm{~h}$. The area of wound-healing was analyzed by Image J.

\section{Transwell assay}

MCF-7 and T47D transfected with DDX27 over-expression and negative control plasmid were starved with serum-free medium for $4 \mathrm{~h}$. $100 \mu \mathrm{L}$ serum-free medium 
with 20,000 cells and $600 \mu \mathrm{L}$ medium with $10 \%$ serum were added into the upper and lower chamber separately. All the cells migrated to the lower chamber were fixed and stained by paraformaldehyde and crystal violet $48 \mathrm{~h}$ later. Three random fields were counted by Image J software for each chamber.

\section{Cell counting kit-8 assay}

Cell Counting Kit-8 (CCK-8) assay (Dojindo, Kumomoto, Japan) was performed to test the proliferation capability of cells. Cells transfected with DDX27 over-expression and negative control plasmid were seeded in 96-well plates with 2000 cells in each well. After $24 \mathrm{~h}, 48 \mathrm{~h}$ and $72 \mathrm{~h}$ of transfection, we added $10 \mu \mathrm{L}$ CCK- 8 solution in each well and then put the plate back into incubator for 2 h. Finally, we used Anthos 2010 Microplate Reader (Anthos Labtec Instruments $\mathrm{GmbH}$, Austria) to detect the OD value at $450 \mathrm{~nm}$.

\section{Statistical analysis}

In this study, GraphPad Prism 8.0 (La Jolla, CA, USA) and SPSS 24.0 (Chicago, IL, USA) were performed to analyze the statistics. Results of our experiments were shown as the mean \pm standard deviation (SD) for three times independently. Analysis of two groups were implemented by Student's independent $\mathrm{t}$ test. Pearson chi-square test, Logistic regression and Fisher's exact test were carried out to access the correlation of DDX27 and clinicopathological factors. The relevance between DDX27 and OCT4 was calculated by Spearman correlation analysis. The probabilities of survival were assessed by Kaplan-Meier assay. The condition of OS and DFS were assessed by Cox regression. Statistically significant probability values were defined as $\leq 0.05$.

\section{Results}

\section{Expression of DDX27 in breast cancer}

Analysis based on TCGA-BRCA database showed that DDX27 was significantly high expressed in cancer whether it's a paired analysis or not $(p<0.0001$, Fig. 1a, b). Results of the UALCAN website also proved that the protein expression of DDX27 in CPTAC database was significantly higher in breast cancer than in normal samples $(p<0.0001$, Fig. 1c). We evaluated DDX27 expression in 24 pairs of breast cancer samples via western blot assay and confirmed that DDX27 was significantly high expressed in cancer than matched normal tissue $(p<0.0001$, Fig. $1 \mathrm{~d})$. Then, we performed IHC to assess the expression of DDX27 in 165 breast cancer patients and found DDX27 was expressed in nucleus (Fig. 2a-d). As a result, DDX27 was significantly highly expressed in cancer comparing to the normal breast tissue (11/40, $27.5 \%)$ and there were 97 breast cancer samples (58.8\%) with high-expressed DDX27 and 68 samples (41.2\%) with low expression.

\section{Association of DDX27 expression with clinicopathological factors and prognosis}

Association between DDX27 and clinicopathological characteristics were performed to access the influence of DDX27 in breast cancer patients. Univariate analysis (Table 1 ) suggested that DDX27 was positively associated with larger tumor size $(p=0.0005)$, positive lymph nodes $(p=0.0008)$, higher histological grade $(p=0.0040)$, higher ki-67 $(p=0.0063)$ and later TNM stage $(p<0.0001)$ in 165 breast cancer patients. Analysis of UALCAN showed that high expression of DDX27 was significantly related to clinical stage and molecular subtypes (Additional file 1: Figure S1a, b), which had the consistent result with our analysis in clinical stage but not in the molecular subtypes.

Bioinformatic analysis according to Kaplan-Meier plotter and Log-Rank test proved that higher expression of DDX27 was significantly relevant to worse OS in breast cancer ( $p=0.0013$, Fig. 3a). Further, we analyzed the implication of DDX27 on the prognosis in terms of different molecular subtypes and found that the shorter OS associated with DDX27 was especially showed in Luminal B breast cancer $(p=0.00083)$ and Basal-like breast cancer $(p=0.028)$ (Fig. $3 \mathrm{~b}-\mathrm{e})$. Moreover, we also found that higher expression of DDX27 could lead to a shorter OS in patients with lymph nodes metastasis compared to the patients without metastasis $(p=0.38$ in lymph node negative and $p=0.0081$ in lymph node positive, Fig. 3f, g).

Our analysis of 165 breast cancer patients had a consistent result with the bioinformatic analysis on prognosis. The Kaplan-Meier analysis and Log-Rank test suggested that DDX27 was positively and closely connected with shorter OS and DFS respectively $(p=0.0087$ for OS and $p=0.0235$ for DFS, Fig. 3h, i). Furthermore, we found that DDX27 expression $(p=0.017)$, tumor size $(p=0.0004)$, lymph node status $(p<0.0001)$, histological grade $(p=0.0004)$ and TNM stage $(p<0.0001)$ were in connection with worse OS in univariate Cox regression, and multivariate analysis showed the independent factors contained tumor size $(p=0.032)$, lymph node status $(p=0.013)$ and histological grade $(p=0.015)$ (Table 2). DDX27 expression $(p=0.0289)$, tumor size $(p=0.0004)$, lymph node status $(p<0.0001)$ and TNM stage $(p=0.0001)$ were correlated to worse DFS in univariate analysis. Multivariate analysis proved that tumor size $(p=0.032)$ and lymph node status $(p=0.018)$ were related to DFS independently (Table 3 ). Therefore, high expression of DDX27 was closely connected with 

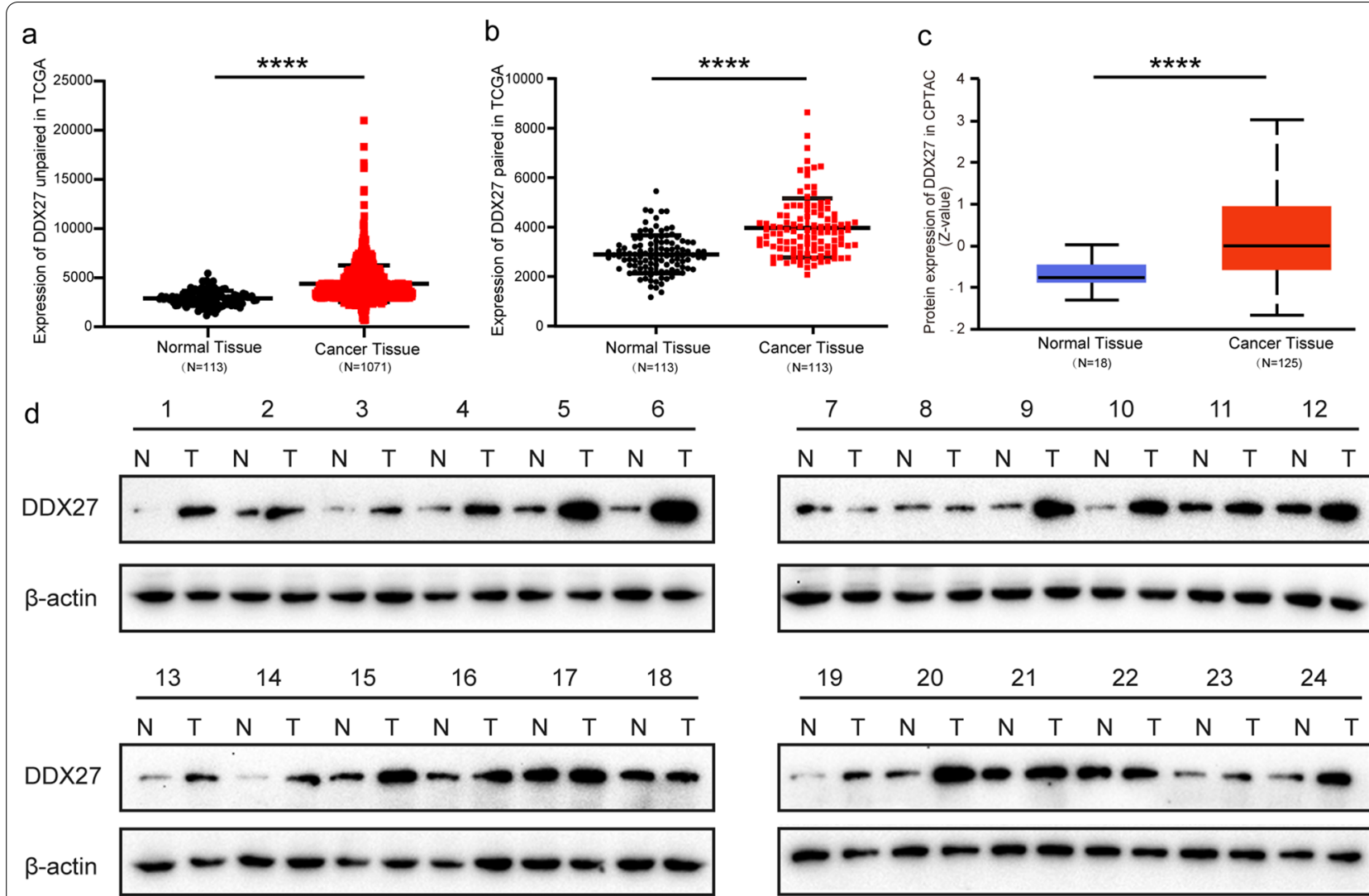

$(\mathrm{N}=113)$ $(N=125)$

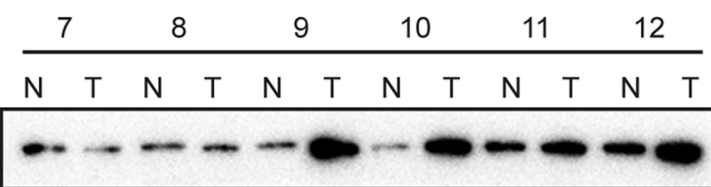

Fig. 1 Expression of DDX27 in breast cancer. a DDX27 was significantly high-expressed in breast cancer than normal tissue in unpair analysis based on TCGA-BRCA database $(t=14.713$ and $p<0.0001)$. b DDX27 was significantly high-expressed in breast cancer than normal tissue in paired analysis based on TCGA-BRCA database $(t=7.804$ and $p<0.0001)$. c Protein expression of DDX27 was significantly higher in breast cancer than normal tissue based on CPTAC database $(p<0.0001)$. $\mathbf{d}$ DDX27 was high-expressed in fresh breast cancer tissue compared with matched normal tissue $(n=24$, $p<0.0001) .{ }^{*} p<0.05,{ }^{* *} p<0.01,{ }^{* * *} p<0.001$, and ${ }^{* * *} p<0.0001$

different clinicopathological factors and resulted in a worse prognosis in breast cancer.

\section{DDX27 promote breast cancer by enhancing stem cell-like properties}

DDX27 was proved to act as a promoter in colorectal cancer by affecting the stem cell-like characteristics [22]. Aimed to excavate the influence of DDX27 on stem cell-like properties in breast cancer, we analyzed the relevance between the expression of DDX27 and stemness biomarkers in TCGA-BRCA database. Results proved that DDX27 had positive correlation with the expression of OCT4 $(p<0.0001)$ and SOX2 $(p=0.0032)$ (Fig. 5a, b). OCT4 is a classical biomarker correlated to breast cancer stem cells and has the expressed location in cell nucleus. In order to explore whether DDX27 affects the stem celllike characteristics in breast cancer, we analyzed the association between DDX27 and OCT4 in 165 breast cancer patients by IHC staining and confirmed that DDX27 was positively related to the expression level of OCT4 $(p<0.0001, r=0.428$, Fig. $4 a-c)$. Since our research group has proven technology on inducing and cultivating of MCF-7 MS and T47D MS, MCF-7 and T47D changed its morphology into mammospheres after inducing and grew rapidly 7-8 days later [24]. According to previous research of our group, the expression of stemness biomarkers and stem cell-like characteristics were obviously enhanced in MCF-7 MS and T47D MS [24, 25]. In our research, we confirmed that DDX27 was significantly high-expressed in MCF-7 MS and T47D MS compared to MCF-7 and T47D by western blot (Fig. 5c). To further elucidate DDX27 as a breast cancer stem cell biotarget, we transfected over-expression and negative control plasmid into MCF-7 and T47D cells and found that SOX2 and OCT4 were up-regulated in DDX27 overexpressed cells on protein levels (Fig. 5d).

We also investigated whether DDX27 could impact on proliferation and migration in breast cancer cells. Results of CCK-8 assay proved that overexpression of DDX27 could improve the proliferation ability in MCF-7 

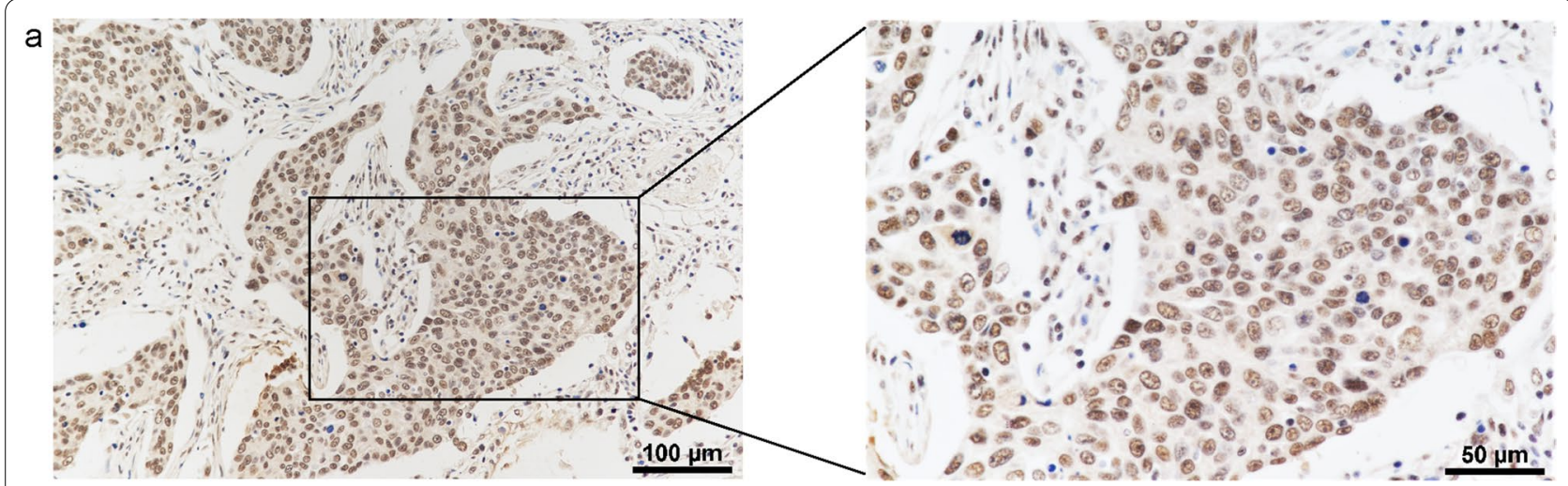

$\mathrm{b}$ \%
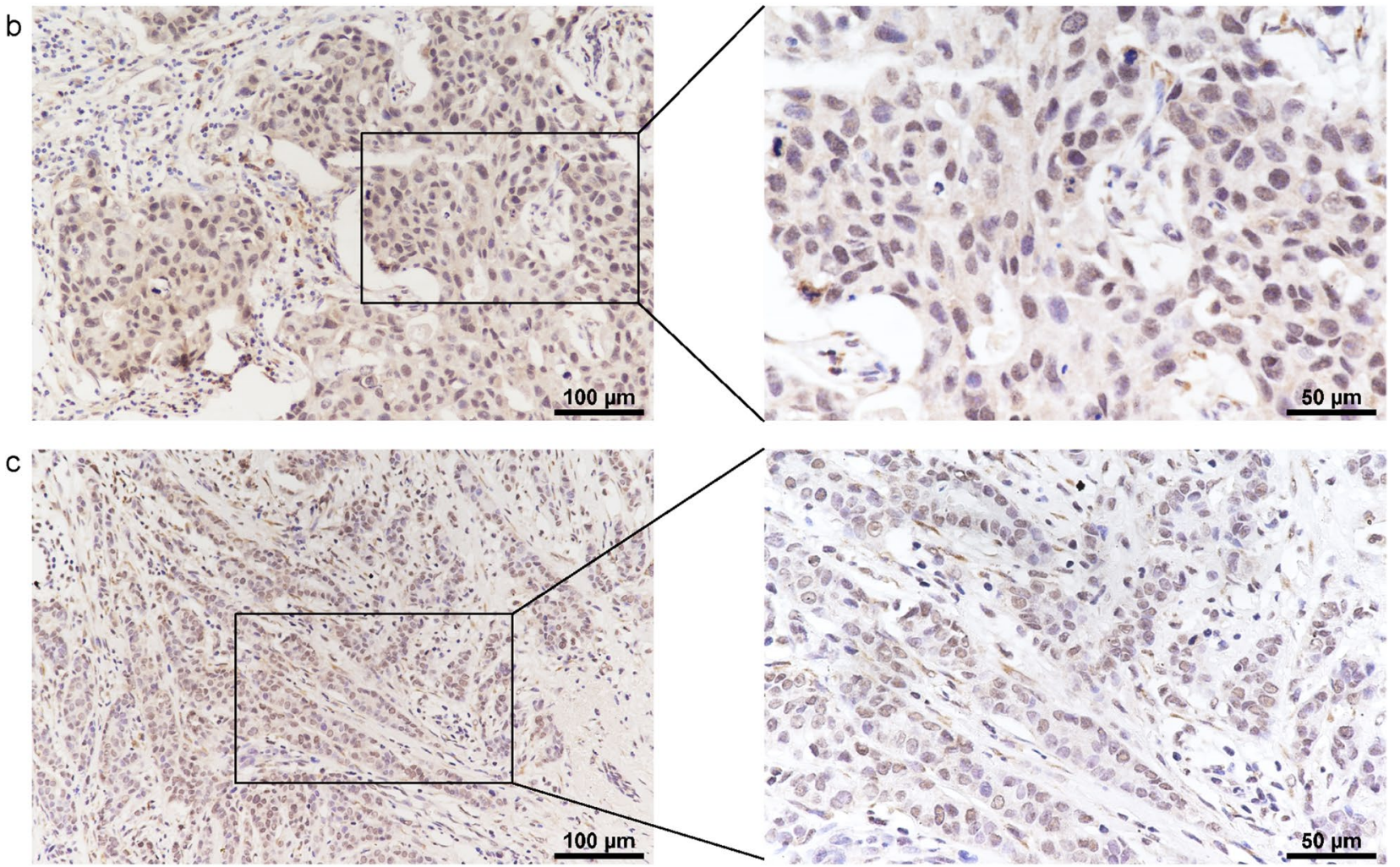

d
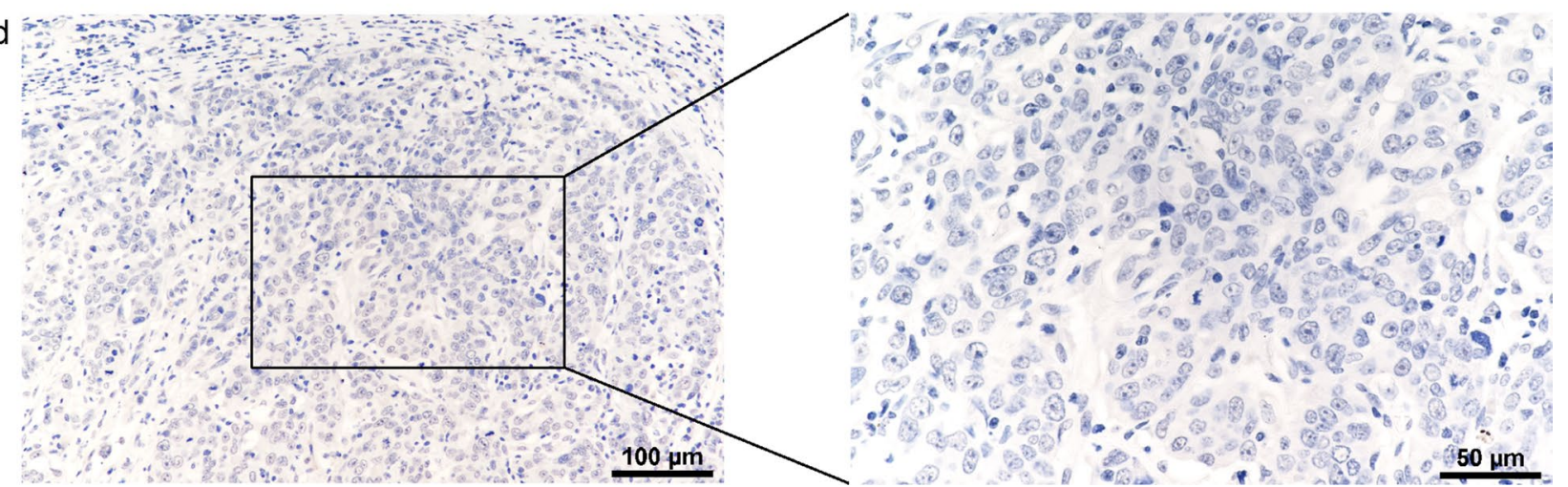

Fig. $2 \mathrm{IHC}$ staining of DDX27. a Deep staining; b Medium staining; c Light staining; d Negative staining 
Table 1 The relationship between DDX27 expression and clinical pathology factors in 165 breast cancer patients

\begin{tabular}{|c|c|c|c|c|c|c|}
\hline \multirow[t]{2}{*}{ Factors } & \multirow[t]{2}{*}{ Number (\%) } & \multicolumn{2}{|l|}{ DDX27 } & \multirow[t]{2}{*}{$x^{2}$} & \multirow[t]{2}{*}{$p$-value } & \multirow[t]{2}{*}{ Crude OR $(95 \% \mathrm{Cl})$} \\
\hline & & Low (\%) & High (\%) & & & \\
\hline Age & & & & 0.253 & $0.6149^{\mathrm{a}}$ & \\
\hline$<60$ & $127(76.97)$ & $51(30.91)$ & $76(46.06)$ & & & Reference \\
\hline$\geq 60$ & $38(23.03)$ & $17(10.30)$ & $21(12.73)$ & & $0.6151^{b}$ & $0.829(0.399-1.722)$ \\
\hline Tumor size & & & & 12.053 & $0.0005^{\mathrm{a}}$ & \\
\hline$<3$ & $95(57.58)$ & $50(30.30)$ & $45(27.27)$ & & & Reference \\
\hline$\geq 3$ & $70(42.42)$ & $18(10.91)$ & $52(31.52)$ & & $0.0007^{b}$ & $3.210(1.642-6.276)$ \\
\hline Lymph node status & & & & 11.334 & $0.0008^{\mathrm{a}}$ & \\
\hline Negative & 109 (66.06) & $55(32.73)$ & $54(32.73)$ & & & Reference \\
\hline Positive & $56(33.94)$ & $13(7.88)$ & $43(26.06)$ & & $0.0010^{b}$ & $3.369(1.631-6.957)$ \\
\hline ER & & & & 3.137 & $0.0765^{a}$ & \\
\hline Negative & $54(32.73)$ & $17(10.30)$ & $37(22.42)$ & & & Reference \\
\hline Positive & $111(67.27)$ & $51(30.91)$ & $60(36.36)$ & & $0.0783^{b}$ & $0.541(0.272-1.072)$ \\
\hline$P R$ & & & & 1.203 & $0.2726^{a}$ & \\
\hline Negative & $54(32.73)$ & $19(11.52)$ & $35(21.21)$ & & & Reference \\
\hline Positive & $111(67.27)$ & $49(29.70)$ & $62(37.58)$ & & $0.2737^{b}$ & $0.687(0.351-1.346)$ \\
\hline HER2 & & & & 0.232 & $0.6298^{a}$ & \\
\hline Negative & $138(83.64)$ & $58(35.15)$ & $80(48.48)$ & & & Reference \\
\hline Positive & $27(16.36)$ & $10(6.06)$ & $17(10.30)$ & & $0.6302^{\mathrm{b}}$ & $1.232(0.526-2.887)$ \\
\hline Ki-67 index (\%) & & & & 7.466 & $0.0063^{\mathrm{a}}$ & \\
\hline$<20$ & $34(20.61)$ & $21(12.73)$ & $13(7.88)$ & & & Reference \\
\hline$\geq 20$ & 131 (79.39) & $47(28.48)$ & $84(50.91)$ & & $0.0076^{b}$ & $2.887(1.326-6.288)$ \\
\hline Molecular subtype & & & & 2.570 & $0.4628^{\mathrm{a}}$ & \\
\hline Luminal A & $23(13.94)$ & $12(7.27)$ & $11(6.67)$ & & & Reference \\
\hline Luminal B & $81(49.09)$ & $35(21.21)$ & $46(27.88)$ & & $0.4470^{b}$ & $1.434(0.566-3.629)$ \\
\hline HER2 & $27(16.36)$ & $10(6.06)$ & $17(10.30)$ & & $0.2845^{b}$ & $1.855(0.598-5.748)$ \\
\hline TNBC & $34(20.61)$ & $11(6.67)$ & $23(13.94)$ & & $0.1377^{b}$ & $2.281(0.768-6.776)$ \\
\hline Histological grade & & & & 8.282 & $0.0040^{\mathrm{a}}$ & \\
\hline I-II & $127(76.97)$ & $60(36.36)$ & $67(40.61)$ & & & Reference \\
\hline III & $38(23.03)$ & $8(4.85)$ & $30(18.18)$ & & $0.0054^{b}$ & $3.358(1.429-7.890)$ \\
\hline TNM stage & & & & 23.606 & $<0.0001^{\mathrm{a}}$ & \\
\hline । & $37(22.42)$ & $28(16.97)$ & $9(16.97)$ & & & Reference \\
\hline$\|$ & 109 (66.06) & $35(21.21)$ & $74(44.85)$ & & $<0.0001^{\mathrm{b}}$ & $6.489(2.767-15.217)$ \\
\hline III & $19(11.52)$ & $5(3.03)$ & $14(8.48)$ & & $0.0005^{b}$ & $9.333(2.647-32.915)$ \\
\hline
\end{tabular}

a $p$-value—came from Pearson Chi-square tests or Fisher's exact test

${ }^{\mathrm{b}} p$-value-came from Logistic regression analyses

and T47D cells (Fig. 5e). Transwell assay confirmed the improvement of migration ability in DDX27 overexpressed cells (Fig. 5f), and the wound-healing assay proved that cells with overexpressed DDX27 could significantly increase the wound-healing ability (Fig. 5g). All of our results suggested that DDX27 could enhance the stem cell-like properties in breast cancer.

\section{DDX27-related signaling pathways}

GSEA was carried out to investigate the potential molecular mechanisms related to DDX27 in breast cancer based on the integrated data from TCGA-BRCA. The results of GSEA indicated that high expression of DDX27 was positively related to NF-kB signaling, embryonic stem cell core, DNA repair, p53 pathway, PI3K-AKTmTOR signaling and the genes which can upregulate MYC targets, hypoxia related genes and downregulate BRCA1 targets (Fig. 6a-h, Table 4). Core enrichment genes of each signaling pathway were shown in Additional file 2: Table S1. This analysis indicated that DDX27 might participate in various signaling pathways in breast cancer. 

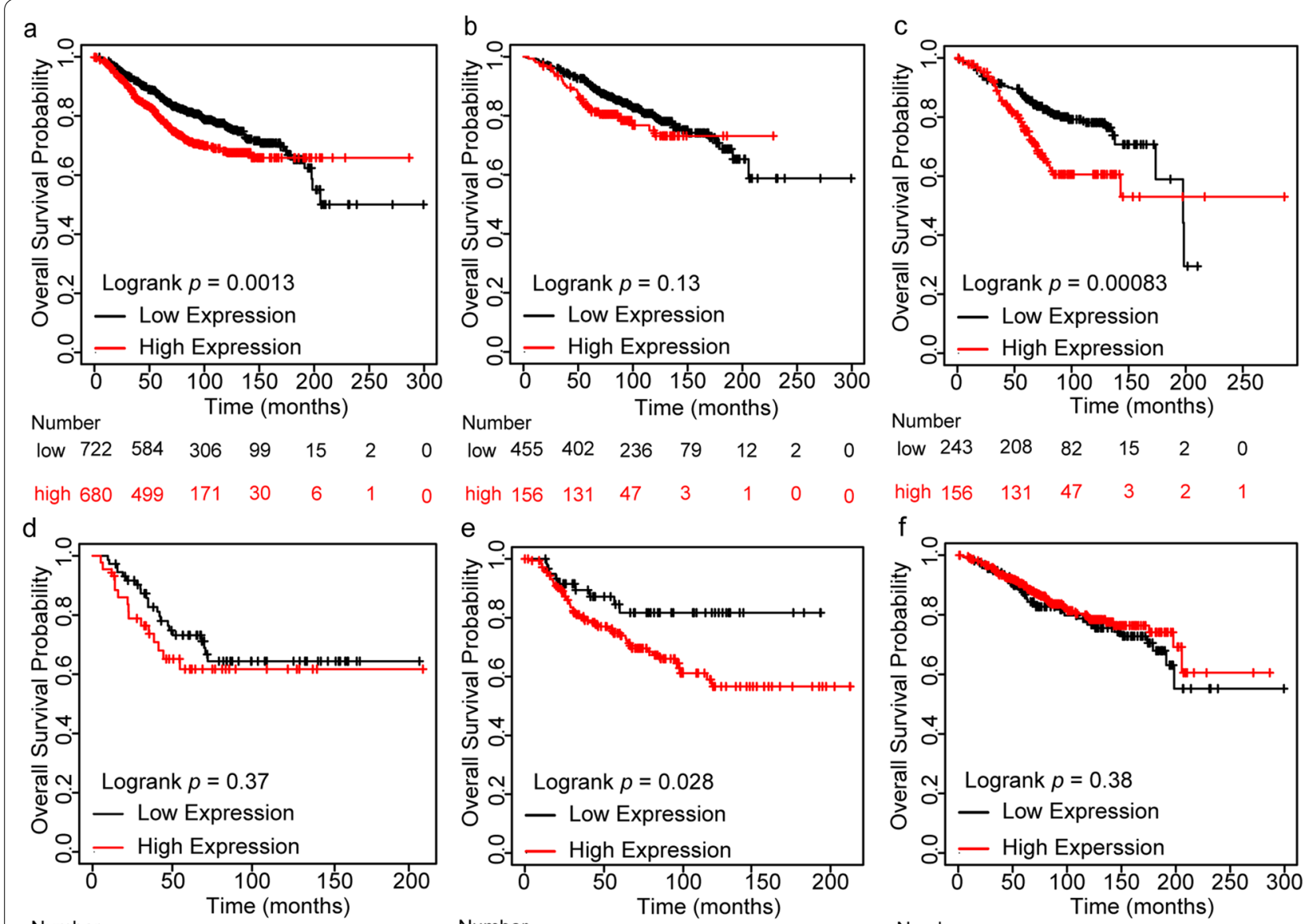

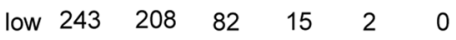

high $\begin{array}{lllllll}156 & 131 & 47 & 3 & 1 & 0 & 0\end{array}$

high $\begin{array}{llllll}156 & 131 & 47 & 3 & 2 & 1\end{array}$
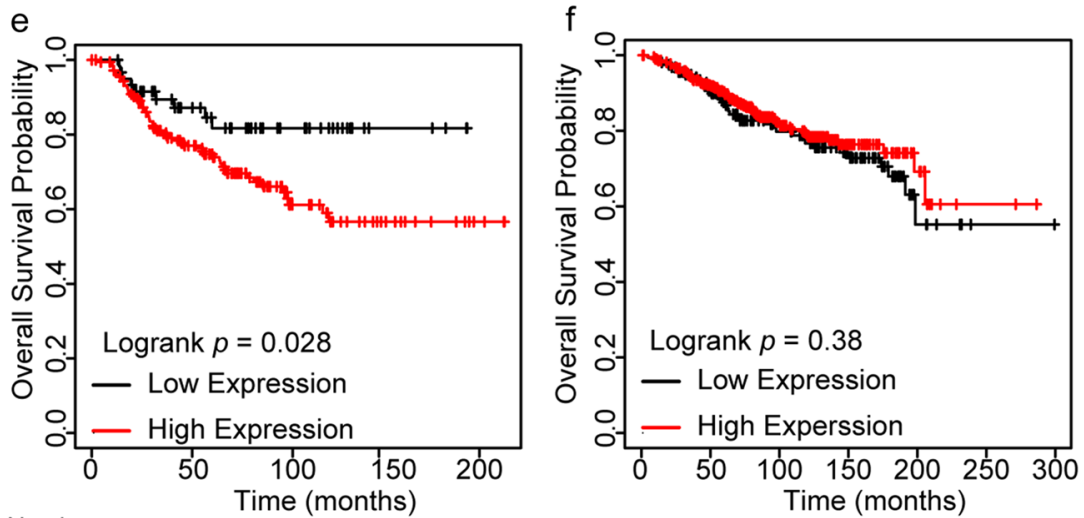

$\begin{array}{lllll}\text { Number } & & & \\ \text { low } 73 & 46 & 19 & 9 & 1 \\ & & 7 & 1 & 1\end{array}$

Number

low 61

$35 \quad 18$

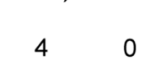

high 44

h

$\mathrm{h}$

Number

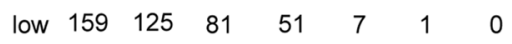

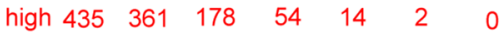

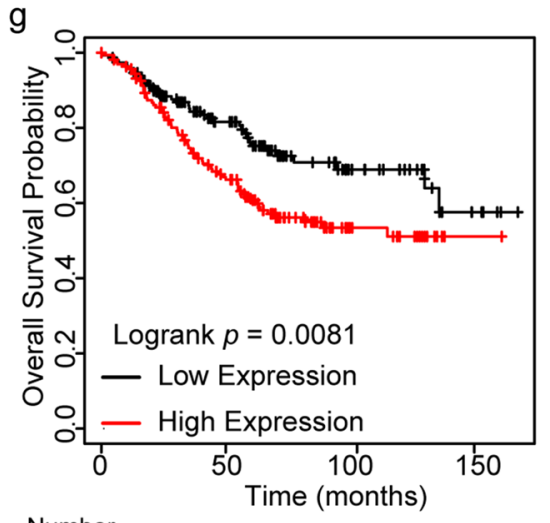

Number

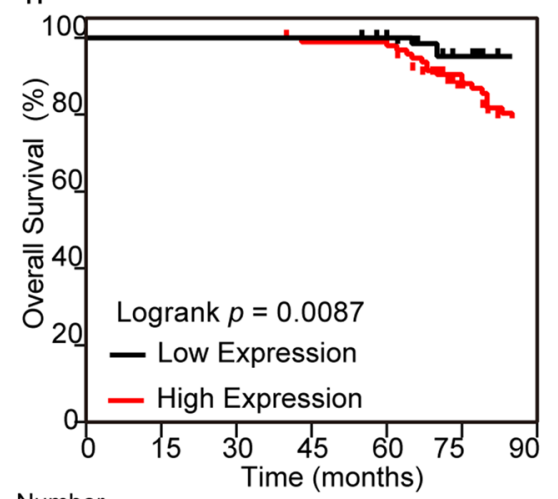

i

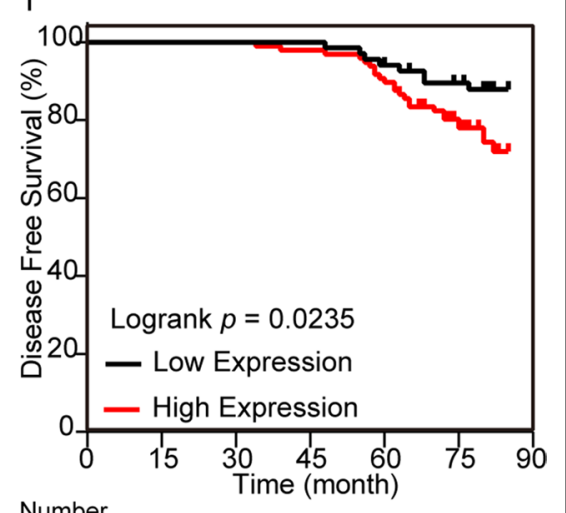

$\begin{array}{lllllllllll}\text { low } 150 & 85 & 30 & 5 & \text { low } 68 & 68 & 68 & 68 & 66 & 56 & 46 \\ \text { high } 163 & 92 & 24 & 1 & \text { high } 97 & 97 & 97 & 95 & 95 & 78 & 59\end{array}$

high $97 \quad 97 \quad 97 \quad 95 \quad 95 \quad 78 \quad 59$

Number

low $68 \quad 68 \quad 68 \quad 68 \quad 64 \quad 56 \quad 46$

Fig. 3 Association between DDX27 expression and prognosis a High DDX27 expression was related to shorter OS in all breast cancer patients in Kaplan-Meier plotter ( $p=0.0013)$. b High DDX27 expression was related to shorter OS in Luminal A breast cancer patients in Kaplan-Meier plotter ( $p=0.13)$. $\mathbf{c}$ High DDX27 expression was related to shorter OS in Luminal B breast cancer patients in Kaplan-Meier plotter ( $p=0.00083)$. $\mathbf{d}$ High DDX27 expression was related to shorter OS in HER2 breast cancer patients in Kaplan-Meier plotter ( $p=0.37)$. e High DDX27 expression was related to shorter OS in Basal-like breast cancer patients in Kaplan-Meier plotter $(p=0.028)$. f High DDX27 expression was not related to shorter OS in lymph node negative breast cancer patients in Kaplan-Meier plotter $(p=0.38)$. g High DDX27 expression was related to shorter OS in lymph node positive breast cancer patients in Kaplan-Meier plotter $(p=0.0081)$. $\mathbf{h}$ High expression of DDX27 was significantly associated with a shorter OS in 165 patients $(p=0.0087)$. i High expression of DDX27 was significantly associated with a shorter DFS in 165 patients $(p=0.0235)$ 
Table 2 Univariate and multivariate Cox regression analysis of DDX27 expression with regard to OS in 165 breast cancer patients

\begin{tabular}{|c|c|c|c|c|}
\hline \multirow[t]{2}{*}{ Characteristics } & \multicolumn{2}{|l|}{ Univariate analysis } & \multicolumn{2}{|l|}{ Multivariate analysis } \\
\hline & $\mathrm{HR}(95 \% \mathrm{Cl})$ & $p$-value & $\mathrm{HR}(95 \% \mathrm{Cl})$ & $p$-value \\
\hline $\mathrm{DD} \times 27$ & $4.437(1.307-15.064)$ & 0.017 & $1.363(0.358-5.189)$ & 0.650 \\
\hline Age & $0.551(0.162-1.871)$ & 0.339 & & \\
\hline Tumor size & $9.220(2.716-31.307)$ & 0.0004 & $4.178(1.127-15.488)$ & 0.032 \\
\hline Lymph node status & $7.613(2.786-20.807)$ & $<0.0001$ & $4.339(1.364-13.804)$ & 0.013 \\
\hline ER & $1.002(0.404-2.483)$ & 0.996 & & \\
\hline$P R$ & $1.025(0.414-2.539)$ & 0.958 & & \\
\hline HER2 & $1.603(0.587-4.378)$ & 0.357 & & \\
\hline Ki-67 index (\%) & $1.640(0.483-5.568)$ & 0.428 & & \\
\hline Histological grade & $4.805(2.024-11.405)$ & 0.0004 & 3.093 (1.243-7.698) & 0.015 \\
\hline TNM stage & $6.045(2.498-14.626)$ & $<0.0001$ & $1.296(0.475-3.533)$ & 0.613 \\
\hline
\end{tabular}

Table 3 Univariate and multivariate Cox regression analysis of DDX27 expression with regard to DFS in 165 breast cancer patients

\begin{tabular}{llccc}
\hline Characteristics & \multicolumn{2}{l}{ Univariate analysis } & & Multivariate analysis \\
\cline { 2 - 3 } & HR(95\% Cl) & $\boldsymbol{p}$-value & HR(95\% Cl) & $1.336(0.575-3.108)$ \\
\hline DDX27 & $2.420(1.095-5.346)$ & 0.0289 & \\
Age & $0.692(0.287-1.672)$ & 0.414 & $2.426(1.081-5.444)$ & 0.501 \\
Tumor size & $3.773(1.804-7.893)$ & 0.0004 & $2.736(1.190-6.290)$ \\
Lymph node status & $4.319(2.135-8.736)$ & $<0.0001$ & \\
ER & $1.040(0.507-2.134)$ & 0.914 & \\
PR & $1.429(0.667-3.061)$ & 0.359 & \\
HER2 & $1.327(0.578-3.049)$ & 0.504 & \\
Ki-67 index (\%) & $2.033(0.716-5.771)$ & 0.183 & \\
Histological grade & $1.736(0.846-3.563)$ & 0.132 & \\
TNM stage & $4.181(1.996-8.785)$ & 0.0001 & \\
\hline
\end{tabular}
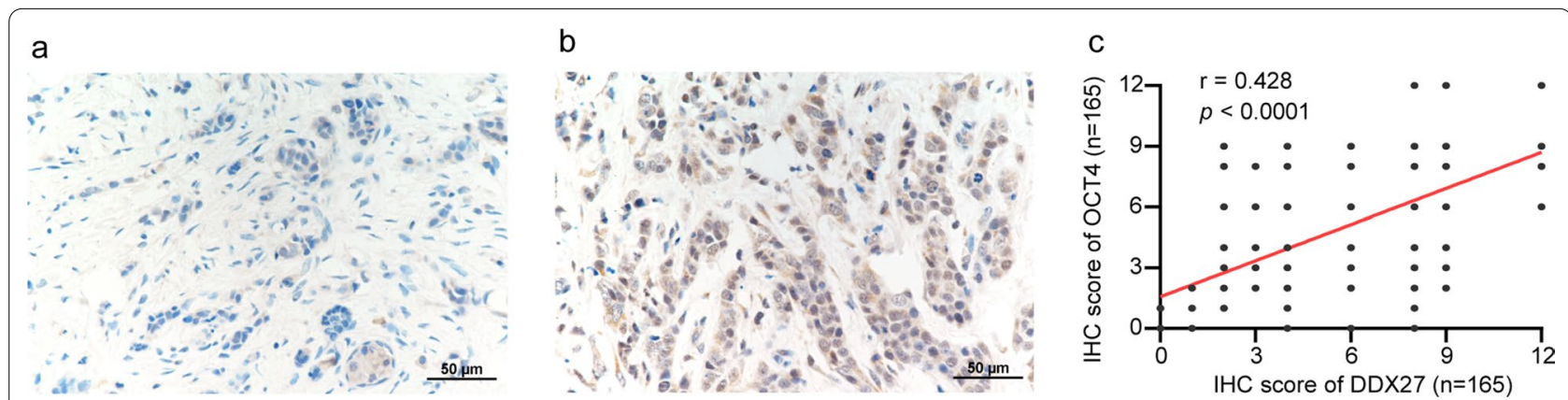

Fig. 4 Relationship between DDX27 and OCT4 by IHC staining. a Low expression of OCT4. b High expression of OCT4. c Correlation between DDX27 and OCT4 expression by $\mathrm{HC}$ staining (Spearman $p<0.0001, r=0.428$ )

\section{Discussion}

Improving prognosis is always a pursuit of cancer therapy. Treatment strategies based on breast cancer molecular types has brought the effective improvement of diagnosis and therapy with better prognosis, which indicates that screening effective biomarkers is always of great significance. As we mentioned before, DDX27 was reported as a promoter and a biomarker with worse prognosis in hepatocellular carcinoma and gastrointestinal cancer [11-13]. Therefore, we analyzed 
the expression level of DDX27 and its influence on breast cancer in this research.

Results of our study confirmed that DDX27 was significantly high-expressed in both bioinformatics analysis and breast cancer samples. Analysis based on DDX27 expression and clinicopathological factors proved that high expression of DDX27 was closely associated with larger tumor size, positive lymph nodes, higher ki-67, higher histological grade and later TNM stage. Analysis of CPTAC database showed that high expression of DDX27 was closely related to the molecular subtypes but we didn't get the same results in the 165 breast cancer patients. Reason for the different results might because the data from CPTAC database totally contained 125 breast cancer patients from different races (Additional file 1: Figure S1c), while our study contained 165 breast cancer patients came from China. Therefore, the influence of DDX27 expression on molecular subtypes in breast cancer should be explored in a larger size of data in the future work.

A consistent conclusion that DDX27 was positively related to a worse prognosis was obtained on KaplanMeier plotter and breast cancer patients. Univariate analysis of OS and DFS in 165 breast cancer patients showed that higher DDX27 expression, larger tumor size, positive lymph nodes and later TNM stage were correlated to worse prognosis, while the larger tumor size and positive lymph nodes were related to a worse prognosis in multivariate analysis. Based on our research, DDX27 is suggested to be a potential biomarker related to prognosis. Since we only analyzed 165 patients, multivariate analysis didn't get a positive result on DDX27 expression. In future, studies including more patients are required to investigate the effect of DDX27 in breast cancer.

Cancer stem cells act as a crucial part in the processes of tumorigenesis, progress, migration, and therapeutic drug resistance [14-16]. DDX27 was proved to act as a promoter in tumorigenesis by impacting stem cell-like characteristics in colorectal cancer [22]. With the inspiration, we explored whether DDX27 could enhance the stem cell-like properties in breast cancer. In this research, we firstly accessed the correction between DDX27 expression and stemness biomarkers. Analysis based on TCGA-BRCA and breast cancer samples confirmed that DDX27 had a positive connection with the expression level of OCT4 significantly. Increased expression of stemness biomarkers and the enhanced abilities of proliferation and migration were shown in DDX27 overexpressed MCF-7 and T47D cells, which indicated that DDX27 could enhance the stem cell-like properties in breast cancer.

The processes of tumorigenesis, development and invasion are regulated by multifarious signaling pathways. In this study, we analyzed the potential molecular mechanism related to DDX27 in breast cancer by GSEA. NF- $\kappa B$ pathway has a great influence on regulating the biological behaviors of breast cancer stem cells $[26,27]$. Enhancement of NF-kB pathway perhaps indicates that DDX27 might facilitate the processes of Epithelial-Mesenchymal Transition (EMT) and have effects on the therapeutic drug resistance in breast cancer [28]. Interestingly, DDX27 was reported to increase cancer progress and metastasis by regulating NF- $\mathrm{KB}$ in colorectal cancer [12]. MYC is known as a crucial factor in cancer stem cells. Overexpression of MYC might induce the ability of self-renewal and multidirectional differentiation in breast cancer stem cells [29]. Connection between DDX27 expression and hypoxia pathway might relate to oxidative stress responses in tumorigenesis in breast cancer. DDX27 correlated to BRCA1 targets and DNA repair, which suggested that DDX27 might take part in the process of genetic mutation. Moreover, DDX27 might regulate the proliferation and migration in breast cancer development on the basis of p53 pathway. We also found that DDX27 was relevant to PI3K-AKT-mTOR pathway, which could act as a therapeutic targe and might provide new ideas for treatment of breast cancer. To sum up, DDX27 might regulate breast cancer via multiple pathways, but the precise regulation mechanism is still unclear. In future research, it is necessary to carry out the mechanistic investigations to explore the influence of DDX27 on the biological properties in breast cancer.

\section{Conclusions}

In conclusion, DDX27 was significantly high-expressed in cancer contrasted to the normal breast tissue. According to our research, the expression level of DDX27 had a closely association with larger tumor, positive lymph nodes, higher histological grade, later TNM stage and a worse prognosis. Our study suggested that DDX27

(See figure on next page.)

Fig. 5 DDX27 promotes the stem cell-like properties of breast cancer cells. $\mathbf{a}, \mathbf{b}$ High expression of DDX27 was positively related to OCT4 and SOX2. c DDX27 was significantly high expressed in MCF-7 MS and T47D MS. $\mathbf{d}$ SOX2 and OCT4 were up-regulated in DDX27 over-expressed cells by western blot. $\mathbf{e}$ Proliferation abilities of breast cancer cells by CCK-8 assay. $\mathbf{f}$ Migration abilities of breast cancer cells by the Transwell assay. $\mathbf{g}$ Migration abilities of breast cancer cells by the wound-healing assay. ${ }^{*} p<0.05,{ }^{* *} p<0.01,{ }^{* * *} p<0.001$, and ${ }^{* * * *} p<0.0001$ 


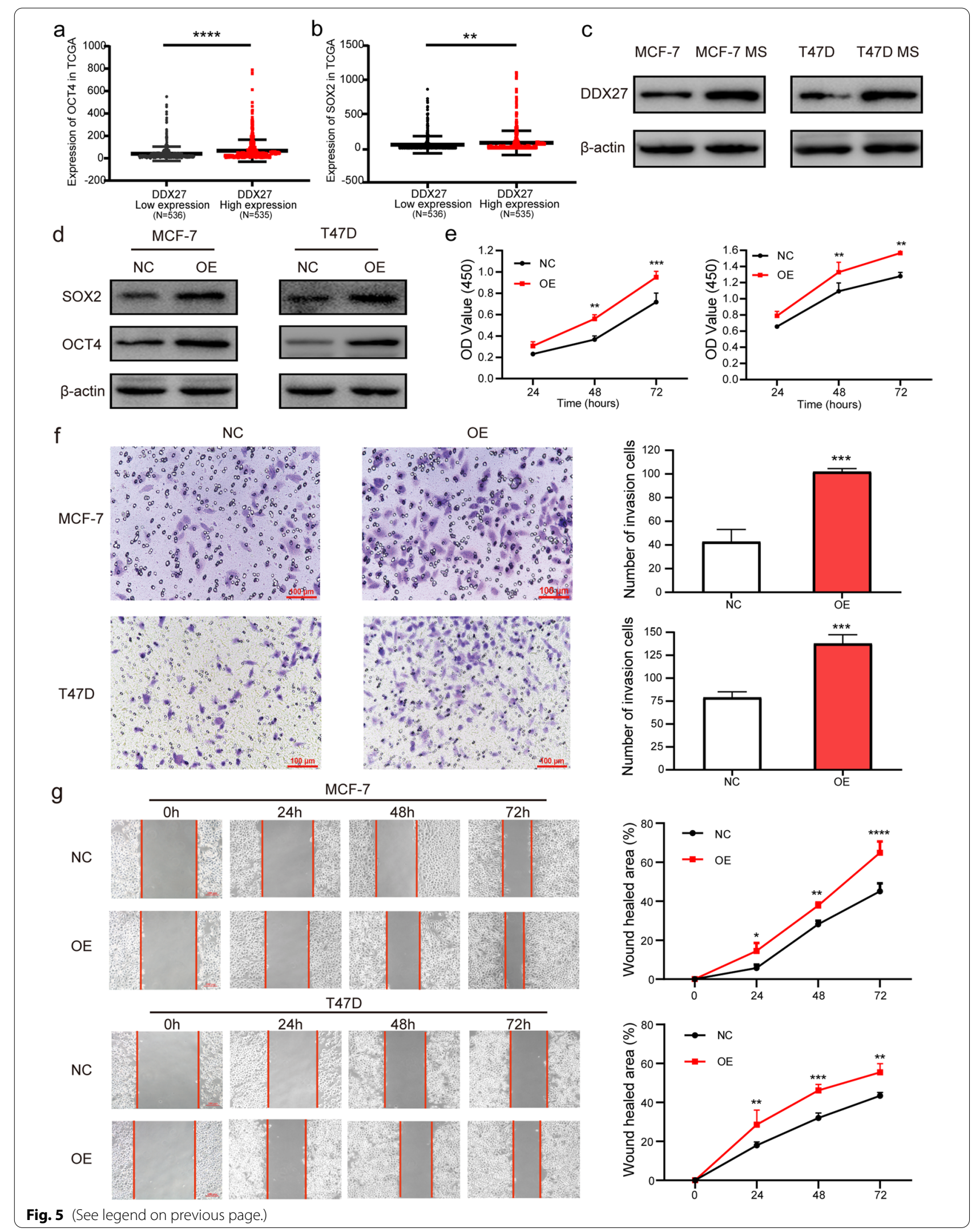




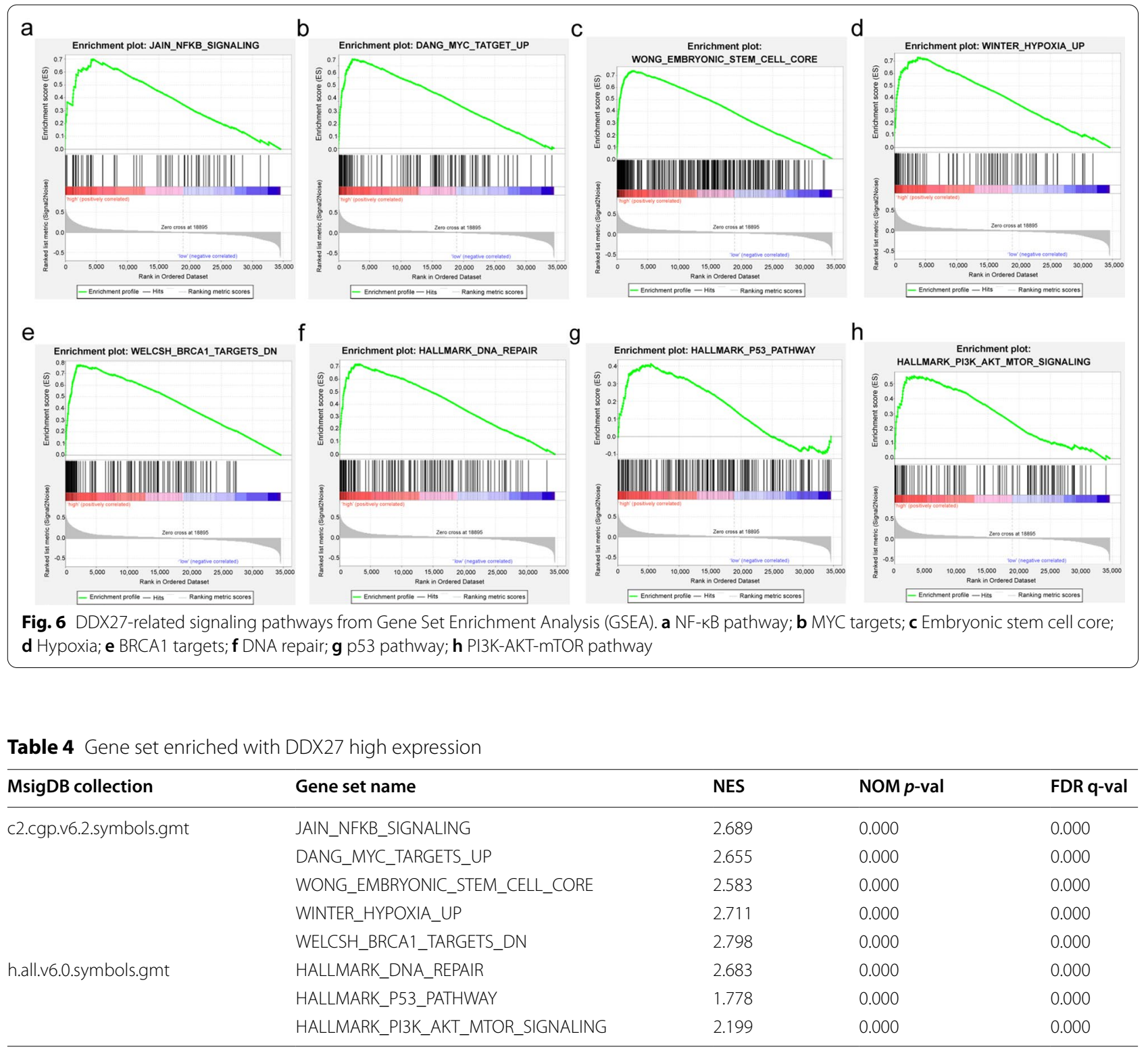

NES normalized enrichment score, NOM nominal, FDR false discovery rate

promoted the evaluation of breast cancer by influencing stem cell-like properties and the exploration of DDX27related signaling pathways had the potential significance on figuring out the molecular mechanism of breast cancer development. In short, DDX27 is bound up with the poor prognosis by enhancing stem cell-like properties and may become a potential therapeutic target in breast cancer.

\section{Abbreviations}

DDX27: DEAD-box helicase 27; IHC: Immunohistochemistry; GSEA: Gene set enrichment analysis; OS: Overall survival; DFS: Disease free survival; TCGABRCA: The Cancer Genome Atlas-Breast Cancer; CPTAC: Clinical Proteomic Tumor Analysis Consortium; MsigDB: Molecular Signatures Database; ER:
Estrogen receptor; PR: Progesterone receptor; HER2: Human epidermal growth factor receptor 2; PBS: Phosphate-buffered saline; BSA: Bovine serum albumin; DAB: Diaminobenzidine; CCK-8: Cell Counting Kit-8; NES: Normalized enrichment score; EMT: Epithelial-mesenchymal transition.

\section{Supplementary Information}

The online version contains supplementary material available at https://doi. org/10.1186/s12967-021-03011-0.

Additional file 1: Figure S1. Protein expression of DDX27 in breast cancer based on CPTAC database. (a) Relationship of DDX27 expression and clinical stage in CPTAC database. (b) Relationship of DDX27 expression and molecular subtypes in breast cancer based on CPTAC database. (c) Relationship of DDX27 expression and patients' races in CPTAC database. ${ }^{*} p<0.05,{ }^{* *} p<0.01,{ }^{* * *} p<0.001$, and ${ }^{* * * *} p<0.0001$ 
Additional file 2: Table S1. Core enrichment genes in DDX27 related pathways.

\section{Acknowledgements}

The authors would like to thank teachers and students for their help. The authors would like to thank all reviewers for their valuable comments.

\section{Authors' contributions}

SL, SC and FJ designed the study. FJ helped in implementing the research. SC helped in reviewing the manuscript. SL did the experiment based on fresh breast tissue and breast cancer cell lines, also wrote the main manuscript. JM collected breast cancer sections and performed on IHC. AZ collected breast cancer tissue after surgery and contributed to statistical analysis of laboratorial experiment. XS did the work of bioinformatics analysis. SL, XS, SC and FJ revised the article according to the reviewers' opinion. All authors read and approved the final manuscript.

\section{Funding}

This work was supported by National Natural Science Foundation of China (82073282) and China Postdoctoral Science Foundation (2020M681018).

\section{Availability of data and materials}

The datasets analyzed for this study can be found in the TCGA repository (https://cancergenome.nih.gov/).

\section{Declarations}

\section{Ethics approval and consent to participate}

The study was supported by Ethics Review Committee of the First Affiliated Hospital of China Medical University (AF-SOP-07-1.1-01) and they claimed to approve this study. All procedures performed in studies involving human participants were in accordance with the ethical standards of the institutional and national research committee and with the Helsinki declaration and its later amendments or comparable ethical standards. The plans for the use of the data were approved. The need of written informed consent from the patients was waived due to the retrospective nature of the study.

\section{Consent for publication}

Not applicable.

\section{Competing interests}

The authors declare that they have no competing interests.

\section{Author details}

${ }^{1}$ Department of Breast Surgery, The First Affiliated Hospital of China Medical University, Shenyang, Liaoning Province, China. ${ }^{2}$ Department of Pharmacology, School of Pharmacy, China Medical University, Shenyang, Liaoning Province, China. ${ }^{3}$ Department of Microbial and Biochemical Pharmacy, School of Pharmacy, China Medical University, Shenyang, Liaoning Province, China.

Received: 12 May 2021 Accepted: 23 July 2021

Published online: 06 August 2021

\section{References}

1. Sung H, Ferlay J, Siegel RL, Laversanne M, Soerjomataram I, Jemal A, et al. Global cancer statistics 2020: GLOBOCAN estimates of incidence and mortality worldwide for 36 cancers in 185 countries. CA Cancer J Clin. 2021. https://doi.org/10.3322/caac.21660.

2. Rocak S, Linder P. DEAD-box proteins: the driving forces behind RNA metabolism. Nat Rev Mol Cell Biol. 2004;5(3):232-41.

3. Linder P, Jankowsky E. From unwinding to clamping - the DEAD box RNA helicase family. Nat Rev Mol Cell Biol. 2011;12(8):505-16.

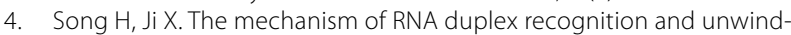
ing by DEAD-box helicase DDX3X. Nat Commun. 2019;10(1):3085.
5. Hondele M, Sachdev R, Heinrich S, Wang J, Vallotton P, Fontoura BMA, et al. DEAD-box ATPases are global regulators of phase-separated organelles. Nature. 2019;573(7772):144-8.

6. Tsai TY, Wang WT, Li HK, Chen WJ, Tsai YH, Chao CH, et al. RNA helicase DDX3 maintains lipid homeostasis through upregulation of the microsomal triglyceride transfer protein by interacting with HNF4 and SHP. Sci Rep. 2017;7: 41452.

7. Li Z, Zhou M, Cai Z, Liu H, Zhong W, Hao Q, et al. RNA-binding protein DDX1 is responsible for fatty acid-mediated repression of insulin translation. Nucleic Acids Res. 2018;46(22):12052-66.

8. Sarkar M, Ghosh MK. DEAD box RNA helicases: crucial regulators of gene expression and oncogenesis. Front Biosci. 2016;21:225-50.

9. Kellner M, Rohrmoser M, Forne I, Voss K, Burger K, Muhl B, et al. DEAD-box helicase DDX27 regulates $3^{\prime}$ end formation of ribosomal 47S RNA and stably associates with the PeBoW-complex. Exp Cell Res. 2015;334(1):146-59.

10. Bennett AH, O'Donohue MF, Gundry SR, Chan AT, Widrick J, Draper I, et al. RNA helicase, DDX27 regulates skeletal muscle growth and regeneration by modulation of translational processes. PLoS Genet. 2018;14(3): e1007226.

11. Tsukamoto Y, Fumoto S, Noguchi T, Yanagihara K, Hirashita Y, Nakada C, et al. Expression of DDX27 contributes to colony-forming ability of gastric cancer cells and correlates with poor prognosis in gastric cancer. Am J Cancer Res. 2015;5(10):2998-3014.

12. Tang J, Chen H, Wong CC, Liu D, Li T, Wang X, et al. DEAD-box helicase 27 promotes colorectal cancer growth and metastasis and predicts poor survival in CRC patients. Oncogene. 2018;37(22):3006-21.

13. Wang $D$, Zhu ZZ, Jiang $H$, Zhu J, Cong WM, Wen BJ, et al. Multiple genes identified as targets for 20q13.12-13.33 gain contributing to unfavorable clinical outcomes in patients with hepatocellular carcinoma. Hepatol Int. 2015;9(3):438-46.

14. Miyoshi N, Mizushima T, Doki Y, Mori M. Cancer stem cells in relation to treatment. Jpn J Clin Oncol. 2019;49(3):232-7.

15. Clarke MF, Dick JE, Dirks PB, Eaves CJ, Jamieson CH, Jones DL, et al. Cancer stem cells-perspectives on current status and future directions: AACR workshop on cancer stem cells. Cancer Res. 2006;66(19):9339-44.

16. Pece S, Tosoni D, Confalonieri S, Mazzarol G, Vecchi M, Ronzoni S, et al. Biological and molecular heterogeneity of breast cancers correlates with their cancer stem cell content. Cell. 2010;140(1):62-73.

17. D'Oronzo S, Silvestris E, Lovero D, Cafforio P, Duda L, Cormio G, et al. DEAD-box helicase $4(\mathrm{Ddx} 4)(+)$ stem cells sustain tumor progression in non-serous ovarian cancers. Int J Mol Sci. 2020. https://doi.org/10. 3390/ijms21176096.

18. Zhou F, Liu Y, Rohde C, Pauli C, Gerloff D, Kohn M, et al. AML1-ETO requires enhanced C/D box snoRNA/RNP formation to induce selfrenewal and leukaemia. Nat Cell Biol. 2017;19(7):844-55.

19. Santoriello C, Sporrij A, Yang S, Flynn RA, Henriques T, Dorjsuren B, et al. RNA helicase DDX21 mediates nucleotide stress responses in neural crest and melanoma cells. Nat Cell Biol. 2020;22(4):372-9.

20. Alqahtani H, Gopal K, Gupta N, Jung K, Alshareef A, Ye X, et al. DDX17 (P72), a Sox2 binding partner, promotes stem-like features conferred by Sox 2 in a small cell population in estrogen receptor-positive breast cancer. Cell Signal. 2016;28(2):42-50.

21. Kao SH, Cheng WC, Wang YT, Wu HT, Yeh HY, Chen YJ, et al. Regulation of miRNA biogenesis and histone modification by K63-polyubiquitinated DDX17 controls cancer stem-like features. Cancer Res. 2019;79(10):2549-63.

22. Yang C, Li D, Bai Y, Song S, Yan P, Wu R, et al. DEAD-box helicase 27 plays a tumor-promoter role by regulating the stem cell-like activity of human colorectal cancer cells. Onco Targets Ther. 2019;12:233-41.

23. Lanczky A, Nagy A, Bottai G, Munkacsy G, Szabo A, Santarpia L, et al. miRpower: a web-tool to validate survival-associated miRNAs utilizing expression data from 2178 breast cancer patients. Breast Cancer Res Treat. 2016;160(3):439-46.

24. Yan Y, Liu F, Han L, Zhao L, Chen J, Olopade OI, et al. HIF-2alpha promotes conversion to a stem cell phenotype and induces chemoresistance in breast cancer cells by activating Wnt and Notch pathways. J Exp Clin Cancer Res. 2018;37(1):256.

25. Zheng A, Song X, Zhang L, Zhao L, Mao X, Wei M, et al. Long noncoding RNA LUCAT1/miR-5582-3p/TCF7L2 axis regulates breast 
cancer stemness via Wnt/beta-catenin pathway. J Exp Clin Cancer Res. 2019;38(1):305.

26. Hayden MS, Ghosh S. Shared principles in NF-kappaB signaling. Cell. 2008;132(3):344-62.

27. Shostak K, Chariot A. NF-kappaB, stem cells and breast cancer: the links get stronger. Breast Cancer Res. 2011;13(4):214.

28. Huber MA, Azoitei N, Baumann B, Grunert S, Sommer A, Pehamberger $H$, et al. NF-kappaB is essential for epithelial-mesenchymal transition and metastasis in a model of breast cancer progression. J Clin Invest. 2004;114(4):569-81.
29. Yoshida GJ. Emerging roles of Myc in stem cell biology and novel tumor therapies. J Exp Clin Cancer Res. 2018;37(1):173.

\section{Publisher's Note}

Springer Nature remains neutral with regard to jurisdictional claims in published maps and institutional affiliations.
Ready to submit your research? Choose BMC and benefit from:

- fast, convenient online submission

- thorough peer review by experienced researchers in your field

- rapid publication on acceptance

- support for research data, including large and complex data types

- gold Open Access which fosters wider collaboration and increased citations

- maximum visibility for your research: over 100M website views per year

At BMC, research is always in progress.

Learn more biomedcentral.com/submissions 